\title{
Effect of Scapular Brace on the Pulmonary Function and Foot Pressure of Elderly Women with Forward Head Posture
}

\author{
Eun-Kyung Kim', Dong-Kyu Lee
}

'Department of Physical Therapy, Gangdong University, Chungcheongbuk-do; ${ }^{2}$ Department of Physical Therapy, Sunhan Hospital, Gwangju, Korea

Purpose: Changes in the curvature of the vertebral columns of elderly women with increasing age causes various side effects and disorders. Therefore, this study was conducted to evaluate the effectiveness of the 8-figure scapular brace to improve pulmonary function and balance ability based on lung capacity and foot pressure by increasing the vertebral curvature.

Methods: Seventeen elderly women with a forward head posture were selected. Women were asked to wear the 8-figure scapular brace and the forced expiratory volume in 1 second (FEV1) and forced vital capacity (FVC) were measured, as were changes in foot pressure. Measurements were conducted three times each and the mean values were used for subsequent analyses. For static evaluation, we used the paired t-test to identify differences between pre and post values.

Results: There was no significant difference in FEV1 and FVC before and after use of the brace ( $p>0.05)$; however, there was a significant decrease in forefoot pressure and an increase in rearfoot pressure following application of the brace $(p<0.05)$.

Conclusion: Application of the 8-figure scapular brace to correct vertebral curvature in elderly women influenced pressure distribution change from immediate effect body arrange of cervical and thoracic. However, wearing the 8-figure scapular brace may interfere with expansion of the chest and therefore respiratory muscle activity. Accordingly, it is necessary to apply appropriate treatment when wearing a scapular brace and to allow a sufficient intervention period while also providing therapeutic interventions such as posture correction or respiration training.

Keywords: Scapular brace, Forward head posture, Pulmonary function, Foot pressure

\section{서 론}

노화에 따른 척주뒤굽음증(kyphosis)은 구부정한 자세를 취하게 하 고 노인의 신체적, 구조적 자세변화를 가져오게 한다. 노인에게서 나 타나는 등굽이(thoracic curvature)는 연령이 증가함에 따라 증가하고 남성보다 여성에게서 더 증가한다. 여성 노인의 등굽이는 특정한 근 골격계 질환과 관계없이 55세 이후부터 10년마다 6-11\% 증가하여, 65 세 이상의 여성 노인 중 $20-40 \%$ 가 노화로 인한 등굽이가 나타난다. ${ }^{3}$ 등굽이는 수평면에 일곱 번째 등뼈를 기준으로 시상면에서 척추의 각도가 앞쪽으로 증가된 경우를 말한다. 등뼈와 목뼈 사이의 생역학 적 연관성은 목 등굽이의 각도(cervicothoracic curvature)를 결정지으 며,5,6 머리를 앞쪽으로 기울게 하는 전방머리자세(forward head posture, FHP)와 같은 비정상적인 자세를 초래하게 된다.1.6-8

노인들의 과도한 척주뒤굽음증(hyperkyphosis)을 개선하기 위한

Received : Jul 25, 2018 Revised Aug 25, 2018

Accepted Aug 30, 2018

Corresponding author Dong-Kyu Lee

E-mail Idkpt@hanmail.net
방법으로는 수술적 처치와 보존적 방법이 제시되어 왔다. ${ }^{9}$ 난치성 통 증(obstinate pain), 중증 장애, 특이성 폐 기능 손상, 진행성 신경학적 결손이 있는 경우 이외에는 수술적 처치는 특별히 권장하지 않으며, ${ }^{9}$ 등뼈뒤굽음(thoracic kyphosis) 향상을 위한 중재 기반 운동과 척추보 조기(spinal orthoses), 자세교정 테이핑(postural taping) 등 비수술적 처 치를 시행한다..$^{10}$ 척추보조기는 보존적 치료에 효과적이며, 자세교정 에 도움을 주어 신체 무게중심(centre of mass)에 동요를 감소시켜 여 성 노인의 균형능력을 개선하여 낙상을 예방할 수 있다."

여성 노인에서 등굽이는 등뼈와 폐를 압박하여 등뼈의 가동성을 저하시켜 폐의 팽창과 수축 기능을 감소시키고, 등뼈 주위 근육의 활 성 저하 및 호흡근의 약화를 가져오게 된다. ${ }^{12,13}$ 이로 인해 폐활량 측 정시 1 초간 노력성 날숨량(forced expiratory volume in 1 second, FEV1) 과 노력성 폐활량(forced vital capacity, FVC)이 감소하게 되고 ${ }^{14}$ 호흡능 력에 문제가 있는 노인의 경우 정상적인 호흡기능을 가진 노인에 비
Copylight (C)2018 The Korea Society of Physical Therapy

This is an Open Access article distribute under the terms of the Creative Commons Attribution Non-commercial License (Http:// creativecommons.org/license/by-nc/4.0.) which permits unrestricted non-commercial use, distribution, and reproduction in any medium, provided the original work is properly cited. 
해 보다 많은 신체 피로감을 느끼게 된다. ${ }^{12}$ 이를 개선하기 위해서는 증 가된 등굽이를 완화시켜 가슴우리를 확장되게 하고 호흡을 교정하는 동시에 가슴우리 가동성을 증가시키는 것이 중요하다. ${ }^{14}$ Pawlowsky 등15 은 여성노인에게 12 주 동안 유연성 운동과 척추 폄근 증가 운동프로 그램을 실시하여 척추 폄근의 기능을 향상시켜 등굽이를 개선시켰다. 등굽이의 개선은 척주의 정렬을 올바르게 하여 안정적 자세를 취하게 하고 가슴우리를 확장시켜 정상적인 호흡이 가능하게 한다.14,15

노화에 따른 척주굽이 변화로 인하여 등굽이는 척추 몸통의 형태 학적(morphology) 변화를 초래하게 하고, 생역학적으로 서 있는 자세 에서 척추 뭇분절(multisegmental)과 몸통 근육에 부담을 증가시키는 요인으로 작용한다.6,16 이는 척추 움직임 감소와 동작을 제한시켜 균 형 장애를 유발하게 된다.17,18 균형의 동요(perturbation)는 신체 관절 들에 새로운 자세전략(postural strategy)을 초래하게 되고, ${ }^{19}$ 균형 능력 이 감소되어 노인의 낙상 위험을 높이는 중요한 요인이 된다. $11,17,18$

Azadinia 등 ${ }^{20}$ 은 등굽이를 가진 노인에게 등허리엉치뼈 보조기 (thoracolumbaosacral orthosis)인 posture-training support와 spinomed orthosis를 착용시켜 자세 안정성과 균형을 향상시켰다. Lee 등른 둥 근어깨자세를 가진 대상자에게 8자형 어깨보조기를 착용시켜 어깨 뼈의 정렬을 교정하고 작은가슴근 길이를 개선하여 어깨뼈 주변근 육의 정상적인 근활성도를 회복시킬 수 있다고 하였다. Ko 등5은 어깨 전방돌출 자세 대상자에게 8 자형 어깨보조기 적용과 팔 올리기 운 동(arm lifting exercise)을 실시하여 어깨뼈 정렬에 긍정적인 변화를 가 져왔다고 하였다.

이와 같은 선행연구 결과는 여성 노인의 등굽이에 따른 호흡 능력 과 균형 능력을 개선시킬 수 있는 즉각적 방법으로 8자형 어깨보조 기의 적용 가능성을 보여주고 있다. 하지만 여성 노인에게 8 자형 어깨 보조기를 적용하여 척주굽이를 개선하는 연구는 매우 부족한 실정 이다. 따라서 점진적으로 진행되는 생리적 노화현상으로 인한 여성 노인의 척주굽이를 개선하기 위해 8 자형 어깨보조기를 적용하여 즉 각적인 효과로 폐활량과 족저압에 미치는 영향을 알아보고자 한다.

\section{연구 방법}

\section{1. 연구대상}

본 연구의 대상자는 머리척추각도(craniovertebral angle, CVA)가 $49^{\circ}$ 이 하인 전방머리자세를 7,822 가진 65 세 이상의 여성 노인 총 17 명을 표본 추출하였으며, 연구 대상자의 제외 기준은 다음과 같다. 1) 최근 6개월 동안 근골격계 질환이 있는 자, 2) 심한 불안정성 척추, 골다공증이 있 는 자, 3) 심혈관 질환 및 혈관성 질환이 있는 자, 4) 폐 관련 질환 병력이 있는 자, 5) 과거 다리와 발 및 발목 부위를 수술한 자는 연구에서 제외 하였다. 실험에 참여하기 전 모든 대상자들은 본 실험에 대한 설명을
충분히 듣고 목적을 이해하였으며, 실험 전에 자발적으로 참여에 동의 하였다. 연구대상자들의 일반적인 특성은 다음과같다(Table 1).

\section{2. 연구절차}

전방머리자세 대상자들을 선별하기 위해 대상자는 의자에 편안하게 앉아 자연스런 머리자세(natural head posture, NHP)를 유지하고 시각 에 의한 자세 변경을 방지하기 위해 대상자의 전방에 한 지점을 표시 하고 주시하도록 지시하였다. 머리척추각도 측정을 위해 도수 촉진 하여 제7목뼈와 귀구슬(tragus)에 표시하고 대상자로부터 $2 \mathrm{~m}$ 떨어진 곳에서 카메라를 이용해 앉아있는 자세를 촬영하였다. 촬영된 사진 은 NIH Image J 1.32 for Windows (National Institutes of Health, USA) 이 미지 프로세스 프로그램을 사용하여 수직선에 대해 $90^{\circ}$ 의 각도를 이 루는 수평선을 제7목뼈를 지나도록 한 뒤 제7목뼈와 귀구슬을 연결 한 선과 수평선이 이루는 각을 머리척추각도라 정의하였다. 머리척 추각도가작은 각도일수록 하부 목뼈 굽힘이 증가되고 전방머리자세 의 증가를 나타낸다. ${ }^{22}$ 머리척추각도의 측정은 3 회 측정하여 3 회 평 균값을 측정값으로 채택하였다.

Table 1. General characteristics

\begin{tabular}{lc}
\hline & Group $(\mathrm{n}=17)$ \\
\hline Age (year) & $67.05 \pm 2.58$ \\
Weight $(\mathrm{kg})$ & $61.30 \pm 7.47$ \\
Height $(\mathrm{cm})$ & $155.80 \pm 3.95$ \\
CVA $\left(^{\circ}\right)$ & $46.67 \pm 1.28$ \\
\hline
\end{tabular}

Values are presented as mean \pm standard deviation. CVA: craniovertebral angle.

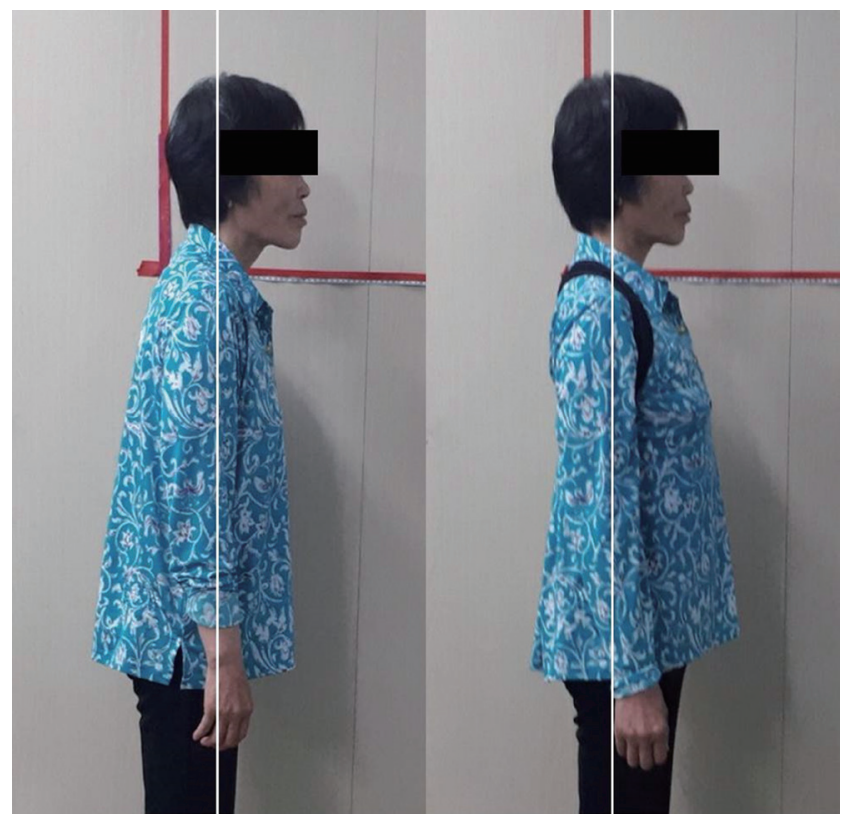

Figure 1. Posture change by wearing 8 figure scapular brace. 
선별 된 전방머리자세 대상자의 척주굽이를 교정하기 위해 8 자형 어깨보조기(Refarm, Korea)를 각 대상자의 양쪽 겨드랑이와 부리돌 기, 가슴우리 중앙을 지나도록 하여 착용하게 하였다. 각 대상자의 척 주굽이와 어깨뼈 위치 교정을 위해 28 인치에서 48 인치까지 사이즈 조 절이 가능한 당김 조절 스트랩을 이용하여 각 대상자의 몸통 넓이에 맞게 조절하고 충분한 긴장감을 준 상태로 적용하였다(Figure 1). ${ }^{23}$ 측 정 전 실험 절차와 실험에 익숙해지도록 자세한 설명을 하였고 각 대 상자의 측정 순서는 무작위로 진행하였으며 측정 전 각 대상자들이 8 자형 어깨보조기에 적응할 수 있도록 익숙화 과정을 10 분간 적용하 였다. 각 측정 결과값은 3 회씩 측정하여 평균값으로 계산하였다.

\section{3. 측정도구}

8 자형 어깨보조기를 착용하기 전과 후 폐활량의 변화를 측정하기 위 해 폐활량 측정기(micro lab spirometer ML3500 MK6, UK)를 사용하 여 1 초간 노력성 날숨량과 노력성 폐활량을 측정하였다. 폐활량 검사 방법은 미국가슴학회(American thoracic society)의 매뉴얼에 따라 다 음과 같은 방법으로 시행하였다. 대상자는 앉은 자세에서 측정하는 동안 공기가 새어 나오는 것을 방지하기 위해 한 손으로 코를 막고 일 회용 마우스피스를 $2 \mathrm{~cm}$ 정도 입 안에 넣고 평상시와 같은 호흡을 3 회 시행한 후 검사자의 구두 신호와 설명에 맞추어 최대 들숨 후 최대 날숨을 약 6초 동안 공기가 없어질 때까지 지속적으로 내쉬도록 요구 하여 측정하였다. FEV1 측정은 대상자가 최대로 숨을 내쉬는 동안 측 정하였고, $\mathrm{FVC}$ 측정은 대상자에게 최대로 숨을 들이마신 후 가능하 면 빠르고 강하게 오래 숨을 내쉬게 하였다. ${ }^{24}$ 측정은 8 자형 어깨 보 조기를 착용하기 전과 착용 후각각 3 회씩 실시하였고 각 측정마다 5 분씩 휴식를 취하도록 하였다. 얻어진 결과 값 중 평균값을 데이터로 사용하였다.

대상자들의 족저압을 측정하기 위해 발바닥 압력 측정기(FDM-S, Zebris Medical GrmbH, Germany)를 사용하였다. 이 측정 도구는 힘판 $(64 \times 40)$ 에 2,560 의 압력감지기가 내장되어 있고 WinFM software를 통 해 발바닥압력 이동을 확인할 수 있는 장비이다. 측정 방법은 힘판 위 에 신발과 양말을 벗은 후 양 발을 올려놓고 팔을 몸통 옆에 편안히 내 려놓은 상태에서 전방 $3 \mathrm{~m}$ 지점에 위치한 표식점을 주시하도록 한 후 발바닥 압력을 측정하였다. 측정 주파수 설정은 $50 \mathrm{~Hz}$, 측정 시간은 10 초로 하여 발바닥 앞쪽과 뒤쪽의 체중지지 분포 비율을 측정하였 다. ${ }^{25}$ 측정은 8 자형 어깨 보조기를 착용하기 전과 착용 후 각각 3 회씩 실시하였고 얻어진 결과 값 중 평균값을 데이터로 사용하였다.

\section{4. 자료분석}

본 연구에서 수집된 자료들은 SPSS 21.0 (SPSS Inc., Chicago, IL, USA)을 이용하여 통계처리하였다. 연구대상자의 일반적인 특성은 기술통계
를 이용하여 평균과 표준편차를 산출하였다. 샤피로-윌크 검정 방법 으로 정규성 검정을 실시하였으며 모든 변수가 정규분포하였다. 8 자 형 어깨보조기 착용에 따른 전후의 변화를 비교하기 위해 대응표본 $\mathrm{t}$ 검정을 실시하였으며 유의수준은 $\alpha=0.05$ 로 설정하였다.

\section{결 과}

\section{8 자형 어깨보조기 착용 전과 착용 후의 1 초간 노력성 날숨량과 노력성 폐활량 비교}

8 자형 어깨보조기 착용 전 평균 $\mathrm{FEV1}$ 은 $2.09 \pm 0.37 \mathrm{~L}$ 이고, 착용 후 평 균 FEV1은 $2.09 \pm 0.35 \mathrm{~L}$ 로 통계학적으로 유의한 차이가 없었다 ( $\mathrm{p}>0.05$ )(Table 2). 8 자형 어깨보조기 착용 전 평균 $\mathrm{FVC}$ 는 $2.45 \pm 0.47 \mathrm{~L}$ 이고, 착용 후 평균 $\mathrm{FVC}$ 는 $2.42 \pm 0.43 \mathrm{~L}$ 로 통계학적으로 유의한 차이 가 없었다 $(\mathrm{p}>0.05)($ Table 2).

\section{8 자형 어깨보조기 착용 전과 착용 후의 족저압 비교}

8 자형 어깨보조기 착용 전 평균 앞쪽 체중지지 분포는 $40.78 \pm 9.05 \%$ 이 고, 착용 후 평균 앞쪽 체중지지 분포는 $33.23 \pm 8.91 \%$ 로 통계학적으로 유의한 차이가 있었다 $(\mathrm{p}<0.05)$ (Table 2). 8 자형 어깨보조기 착용 전 뒤 쪽 체중지지 분포는 $59.25 \pm 9.03 \%$ 이고, 착용 후 뒤쪽 체중지지 분포는 $66.76 \pm 8.91 \%$ 로 통계학적으로 유의한 차이가 있었다 $(\mathrm{p}<0.05)$ (Table 2).

\section{고 찰}

노인은 나이가 들어감에 따라 신체적으로 변화를 겪는다. 척추의 유 연성과 근력 및 관절가동범위의 감소로 인하여 구부정한 자세가 발 생하고 ${ }^{3}$ 폐활량에 문제를 초래하게 된다. ${ }^{12}$ 여성 노인은 이러한 근골 격계 질환 비율이 높아질 뿐만 아니라 관절 및 신체 균형의 문제가 높 게 나타나며, 균형능력의 감소를 보이고 낙상의 위험도가 증가한 다. $3.11,18$

이에 본 연구는 여성 노인의 척주굽이를 개선하기 위해 8 자형 어깨 보조기를 적용하여 즉각적인 효과로 폐활량과 족저압에 미치는 영 향을 알아보고자 하였다. 폐활량 변화를 알아보기 위해 1 초간 노력

Table 2. The comparison of variable on pre and post in inner-group

\begin{tabular}{lcccc}
\hline & Pre & Post & $\mathrm{t}$ & $\mathrm{p}$ \\
\hline FEV1 (L) & $2.09 \pm 0.37$ & $2.09 \pm 0.35$ & -0.047 & 0.963 \\
FVC (L) & $2.45 \pm 0.47$ & $2.42 \pm 0.43$ & 0.652 & 0.524 \\
Front foot (\%) & $40.78 \pm 9.05$ & $33.23 \pm 8.91$ & 3.619 & $0.002^{*}$ \\
Rear foot (\%) & $59.25 \pm 9.03$ & $66.76 \pm 8.91$ & -3.665 & $0.002^{*}$ \\
\hline
\end{tabular}

Values are presented as mean \pm standard deviation. FEV1: forced expiratory volume in 1 second. ${ }^{*} \mathrm{p}<0.05$. 
성 날숨량과 노력성 폐활량을 측정하였다. 연구 결과 8 자형 어깨보 조기 착용 전과 착용 후 폐활량의 평균값은 유의한 차이가 없었다 ( $\mathrm{p}>0.05)$. 둥근어깨자세를 개선하기 위해 20대 젊은 성인을 대상으로 8 자형 어깨보조기를 적용한 Lee 등ㄴㅇㅢ 연구에서는 어깨뼈 뒤쪽 내림 운동만 단독으로 실시하였을 때보다 작은가슴근 스트레칭 후 어깨 보조기를 착용한 상태에서 어깨뼈 뒤쪽 내림 운동을 실시했을 때, 둥 근어깨자세의 정도는 유의하게 감소하였고 짧아진 작은가슴근의 길 이 변화를 주었다.

전방머리자세는 둥근어깨자세를 수반하고 이러한 자세적 기능장 애는 나이가 들어 갈수록 증가한다. ${ }^{326}$ 전방머리자세는 근육의 단축 을 초래하며 이러한 근육들은 호흡에 관여하는 근육으로 목갈비근, 목빗근, 뒤통수아래근으로 날숨에 관여하는 근육들이다. ${ }^{2728}$ 들숨 시 목빗근과 목갈비근은 복장뼈와 갈비뼈를 머리 방향으로 이동시켜 가슴우리의 크기를 확장시키는 역할을 한다. 27.28 또한 등뼈뒤굽음에 따른 신체의 구조적 변화로 가슴우리 팽창에 물리적인 제한을 주고 들숨근육의 단축은 이를 더욱 가중시켜 폐에 도달하는 공기의 양에 영향을 미친다.12

선행연구 결과에서 여성 노인의 생리적 노화에 따른 전방머리자세 는 호흡근육과 가로막의 가동성 및 기능 약화로 인해 폐활량이 감소 한다는 사실을 보여준다. ${ }^{26-28}$ 본 연구에서는 등굽이에 의한 전방머리 자세를 가진 여성노인에게 8 자형 어깨보조기를 착용하게 하여 척주 굽이를 개선하여 폐활량의 변화를 주고자 하였으나 유의한 결과 차 이를 보이지 않았다. 그러나 Bae 등의 의 연구에서는 전방머리자세를 가 진 남자 대학생을 대상으로 인위적으로 중립머리자세를 취하게 하여 노력성 폐활량을 측정한 결과 높은 결과 값을 보여 본 연구와 상반된 결과를 보였다. 이와 같이 선행연구와 다른 결과를 보인 이유는 20대 젊은 남자 대학생과 65 세 이상 여성 노인의 연령 차이를 감안하더라 도 어깨보조기를 착용하기 위한 스트랩의 압박이 가슴우리의 확장 을 제한하여 비정상적인 척주굽이의 개선 변화에도 불구하고 폐활량 을 증가시키지 못한 것으로 사료된다. 더불어 폐 기능의 향상을 위해 서는 노화에 의해 점진적으로 약화되고 불균형해진 호흡 근육의 길 이-장력관계가 개선되어야 하고 호흡보조근의 역할을 제대로 수행할 수 있게 하는 호흡운동프로그램이 수반되어야 할 것으로 생각된다.

노화로 인해 등굽이를 가진 노인은 등빼가 앞으로 굽힘 되어 신체의 무게중심이 앞으로 이동하게 된다.6.11 본 연구에서 8자형 어깨보조기 착용 후 족저압을 측정한 결과 앞쪽 체중지지 분포는 유의하게 감소하 였으며 뒤쪽 체중지지 분포는 유의하게 증가하여 선행연구와 일치하 였다( $<0.05)$. 등굽이가 증가할수록 무게중심이 이동하여 균형능력에 부정적인 영향을 주며, 자세의 변화와 불균형은 활동량의 저하를 야기 한다.18.19 Sinaki과 $\mathrm{Lynn}^{30}$ 의 연구에서 등굽이를 가진 여성 노인에게 척 추보조기를 적용하여 균형과 체중분포에 긍정적인 영향을 보였으며,
Choi ${ }^{31}$ 는 척추 변형과 족저압은 큰 연관성이 있음을 시사하였다.

하지만 어깨보조기를 착용하기 위한 스트랩의 강한 압박은 가슴우 리의 확장을 제한하여 신체의 운동성과 호흡능력을 감소시킨다. 효 과적인 어깨보조기 착용을 위해서는 보조기와 몸통 간 접촉하는 면 적을 넓게 하여 몸통에 가해지는 압력 분산을 효과적으로 이루어지 게 하여야 한다. ${ }^{32}$ 또한 가로막 호흡 시 발생하는 배안(abdominal cavity)의 압력은 몸통 주변의 근육을 활성화하여 균형 능력을 향상시킨 다. 그러나 보조기의 비가역적 압박은 이를 방해하는 요인이 된다.32,33

본 연구 결과 여성 노인의 등굽이에 따른 전방머리자세를 교정하 기 위해 즉각적 효과로 8 자형 어깨보조기를 적용하였을 경우 목뼈와 등뼈의 신체 배열에 영향을 주어 족저압 분포에 변화를 줄 수 있음을 알 수 있었다. 하지만 8 자형 어깨보조기의 착용에 따른 스트랩의 압 박은 호흡근 및 다른 협력근과 보조근들의 활성도를 방해할 수 있 다. ${ }^{34}$ 보조기에 의한 즉각적이고 인위적인 목뼈와 등뼈의 해부학적 구 조 변화는 오랜 시간 동안 점진적으로 퇴행된 여성 노인의 자세 변화 에 의한 등굽이와 전방머리자세에 적응되어 있는 가슴우리와 주변 신체 조직들에 충분한 변화를 주지 못하였고 적절한 호흡 근육의 힘 수준을 생성할 수 있는 기계적인 능력에 변화를 주지 못하였기 때문 에 폐활량에 크게 영향을 주지 못한 것으로 사료된다. 그러므로 8 자 형 어깨 보조기 적용이 폐활량에 영향을 줄 수 있는 충분한 중재 기 간과 더불어 노인의 전방머리자세를 개선하기 위한 자세교정이나 호 흡훈련 등의 치료적 중재의 병행이 필요할 것이다.

본 연구의 제한점은 65 세 이상의 여성 노인만을 대상으로 연구가 진행되어 일반화하기 어렵고 오랜 기간 동안 중재 효과를 비교 못한 점과 다른 자세교정 훈련이나 호흡훈련과 비교하지 못하지 못하였다 는 점이다. 또한 폐활량 측정 시 앉은 자세에서 전방머리자세가 더 증 가함을 감안하지 못하고 앉은 자세에서 폐활량을 측정하였다는 점 이다. 따라서 향후 연구에서는 다양한 연령층의 대상자와 참여 대상 자의 수 및 충분한 중재기간과 여러 물리치료 중재방법에 대한 후속 연구가 필요할 것으로 사료된다.

\section{참고문헌}

1. Hinman MR. Comparison of thoracic kyphosis and postural stiffness in younger and older women. Spine J. 2004:4(4):413-7.

2. Nishiwaki Y, Kikuchi Y, Araya K et al. Association of thoracic kyphosis with subjective poor health, functional activity and blood pressure in the community-dwelling elderly. Environ Health Prev Med. 2007;12(6):24650 .

3. Bartynski WS, Heller MT, Grahovac SZ et al. Severe thoracic kyphosis in the older patient in the absence of vertebral fracture: association of extreme curve with age. AJNR Am J Neuroradiol. 2005;26(8):2077-85.

4. Fon GT, Pitt MJ, Thies AC Jr. Thoracic kyphosis: range in normal subjects. AJR Am J Roentgenol. 1980;134(5):979-83. 
5. Ko CH, Cynn HS, Lee JH et al. Figure-8 strap application: immediate alteration of pectoralis minor length and scapular alignment during armlifting exercise in participants with forward shoulder posture. J Sport Rehabil. 2016;25(3):273-9.

6. Briggs AM, van Dieën JH, Wrigley TV et al. Thoracic kyphosis affects spinal loads and trunk muscle force. Phys Ther. 2007;87(5):595-607.

7. Kim JS, Choi JH, Lee MY. Effect of self-postural control with visual feedback in the foot pressures in the subject with forward head posture. J Kor Phys Ther. 2017;29(4):153-7.

8. Kong YS, Kim YM, Shim JM. Effects of modified cervical exercise on respiratory functions in smartphone users with forward head posture. J Kor Phys Ther. 2016;28(5):292-6.

9. Ailon T, Shaffrey CI, Lenke LG et al. Progressive spinal kyphosis in the aging population. Neurosurgery. 2015;77(Suppl 4):S164-72.

10. Pfeifer M, Kohlwey L, Begerow B et al. Effects of two newly developed spinal orthoses on trunk muscle strength, posture, and quality-of-life in women with postmenopausal osteoporosis: a randomized trial. Am J Phys Med Rehabil. 2011;90(10):805-15.

11. Katzman WB, Sellmeyer DE, Stewart AL et al. Changes in flexed posture, musculoskeletal impairments, and physical performance after group exercise in community-dwelling older women. Arch Phys Med Rehabil. 2007;88(2)192-9.

12. Hawes MC, Brooks WJ. Improved chest expansion in idiopathic scoliosis after intensive, multiple-modality, nonsurgical treatment in an adult. Chest. 2001;120(2):672-4.

13. Burr ML, Phillips KM, Hurst DN. Lung function in the elderly. Thorax 1985;40(1):54-9.

14. Priftis KN, Hager J, Vlachou M et al. Effects of bracing on lung function in idiopathic juvenile kyphosis. Pediatr Pulmonol. 2003;35(2):83-6.

15. Pawlowsky SB, Hamel KA, Katzman WB et al. Stability of kyphosis, strength, and physical performance gains 1 year after a group exercise program in community-dwelling hyperkyphotic older women. Arch Phys Med Rehabil. 2009;90(2):358-61.

16. Ebert R, Campbell A, Kemp-Smith K et al. Lumbar spine side bending is reduced in end range extension compared to neutral and end range flexion postures. Man Ther. 2014;19(2):114-8.

17. Seacrist T, Saffioti J, Balasubramanian $S$ et al. Passive cervical spine flexion: the effect of age and gender. Clin Biomech (Bristol, Avon). 2012;27(4):32633.

18. Aslan UB, Cavlak U, Yagci N et al. Balance performance, aging and falling: A comparative study based on a Turkish sample. Arch Gerontol Geriatr. 2008;46(3):283-92.

19. Chang JS, Lee MH. The comparison of plantar foot pressure distribution in adult and elderly according obstacle heights. J Kor Phys Ther. 2014; 26(4):257-61.
20. Azadinia F, Kamyab M, Behtash H et al. The effects of two spinal orthoses on balance in elderly people with thoracic kyphosis. Prosthet Orthot Int. 2013;37(5):404-10.

21. Lee JH, Cynn HS, Yoon TL et al. The effect of scapular posterior tilt exercise, pectoralis minor stretching, and shoulder brace on scapular alignment and muscles activity in subjects with round-shoulder posture. J Electromyogr Kinesiol. 2015;25(1):107-14.

22. Kim EK, Kim SG. The effect of an active vibration stimulus according to different shoulder joint angles on functional reach and stability of the shoulder joint. J Phys Ther Sci. 2016;28(3):747-51.

23. Cole AK, McGrath ML, Harrington SE et al. Scapular bracing and alteration of posture and muscle activity in overhead athletes with poor posture. J Athl Train. 2013;48(1):12-24.

24. Lima IN, Fregonezi GA, Melo R et al. Acute effects of volume-oriented incentive spirometry on chest wall volumes in patients after a stroke. Respir Care. 2014;59(7):1101-7.

25. Pau M, Leban B, Collu G et al. Effect of light and vigorous physical activity on balance and gait of older adults. Arch Gerontol Geriatr. 2014; 59(3):568-73.

26. Yip CH, Chiu TT, Poon AT. The relationship between head posture and severity and disability of patients with neck pain. Man Ther. 2008;13(2): 148-54.

27. Legrand A, Schneider E, Gevenois PA et al. Respiratory effects of the scalene and sternomastoid muscles in humans. J Appl Physiol. 2003; 94(4):1467-72.

28. Ovechkin A, Vitaz T, de Paleville DT et al. Evaluation of respiratory muscle activation in individuals with chronic spinal cord injury. Respir Physiol Neurobiol. 2010;173(2):171-8.

29. Bae WS, Lee KC, Park SW et al. Effect of the changes in forward head posture and neutral head posture on respiratory. KSIM. 2017;5(1):67-74.

30. Sinaki M, Lynn SG. Reducing the risk of falls through proprioceptive dynamic posture training in osteoporotic women with kyphotic posturing: a randomized pilot study. Am J Phys Med Rehabil. 2002;81(4):2416.

31. Choi HI. (A) study on the relationship between scoliosis and foot. Daegu University. Dissertation of Master's Degree. 2001.

32. Kim YH, Jun SC, Jung DY et al. Biomechanical analysis of different thoracolumbar orthosis designs using finite element method. RWEAT. 2012; 6(1):45-50.

33. Frank C, Kobesova A, Kolar P. Dynamic neuromuscular stabilization \& sports rehabilitation. Int J Sports Phys Ther. 2013;8(1):62-73.

34. Caro CG, Butler J, DuBois AB. Some effects of restriction of chest cage expansion on pulmonary function in man: an experimental study. J Clin Invest. 1960;39:573-83. 